ISSN 0819-2642

ISBN 9780734040039

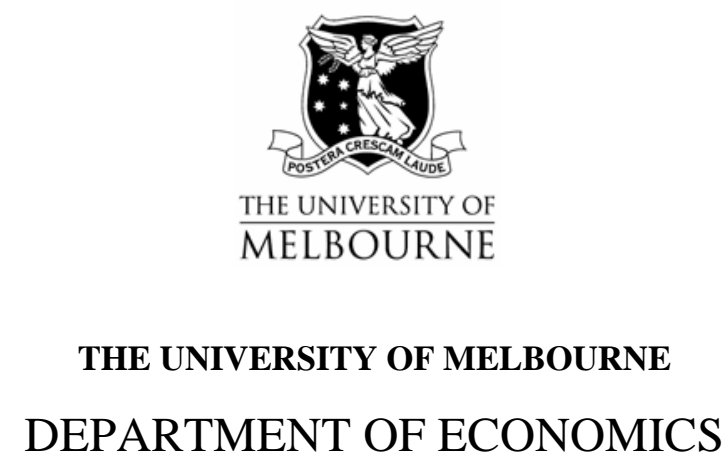

RESEARCH PAPER NUMBER 1037

April 2008

Credential Changes and Education Earnings Premia in Australia

by

Michael Coelli \& Roger Wilkins

Department of Economics

The University of Melbourne

Melbourne Victoria 3010

Australia. 


\title{
Credential Changes and Education Earnings Premia in
}

\author{
Australia *
}

\author{
Michael Coelli ${ }^{\dagger}$ and Roger Wilkins ${ }^{\ddagger}$
}

24 April 2008

Keywords: education, earnings structure, wage premium, credentials, Australia.

JEL Codes: I20, J24, J31

\begin{abstract}
We find that post-school education earnings premia have remained strikingly stable over the 1981 to 2003-04 period in Australia. This stability is in sharp contrast to the rising college premium observed in the US. The observed stability in Australia may in part be due to changes in the credentials earned by individuals entering certain professional occupations during the 1980s and early 1990s, particularly for females. We provide an estimate of the potential effect of within-occupation credential changes on estimates of education earnings premia in Australia over time. Our focus is on credential changes within the nursing and teaching professions, which have moved from predominately certificate and diploma qualifications to university bachelor's degree or higher as the standard qualification.
\end{abstract}

${ }^{*}$ We are indebted to Jeff Borland and seminar participants at the RSSS at ANU, the University of Adelaide, MOTU New Zealand and the University of Melbourne for useful comments and suggestions. The interpretation, opinions expressed and any errors are our own.

${ }^{\dagger}$ Department of Economics, The University of Melbourne

${ }^{\ddagger}$ Melbourne Institute of Applied Economic and Social Research (MIAESR), The University of Melbourne 


\section{Introduction}

Overall earnings inequality has risen in Australia over the past three decades, as it has in many developed countries. It is often claimed that one of the main sources of this rise is skill-biased technological change (SBTC), which has led to increased relative demand for skilled workers over unskilled workers. The strong rise in the wage premium paid to college educated workers in the United States since the beginning of the 1980s has been well documented (Card and DiNardo, 2002). Yet in Australia, both Borland (1999) and Gregory (1995) have provided evidence that the earnings premium of post-secondary educated workers actually fell for both males and females from the late 1960 s to the early 1980 s, then remained quite stable over the 1980 s, and even up until the early to mid-1990s.

We have two objectives in this paper. The first objective is to provide updated measures of education earnings premia in Australia, over the 1981/82 to 2003/04 period. These updated measures will span recent changes in the Australian labour market, including further movement of the industrial relations regime away from centralised award-based wage setting to enterprise and individual level wage bargaining. The Australian economy has also grown considerably since the mid 1990s, with many employers currently citing the difficulty in finding skilled workers.

The most common explanation provided for why education earnings premia did not rise in Australia in the 1980s as they did in the United States is that rising demand for university educated workers was met in Australia by a rapid increase in supply (Borland, 1999). The second objective of this paper is to propose an additional explanation for why measured education earnings premia may have been kept down over the past two decades. We investigate the hypothesis that the wage premium paid to workers who hold more 'traditional' bachelors degrees may in fact have risen, but this rise has been masked by an expansion of the scope of bachelors degree education in Australia since the 1980s. The educational attainment composition of a number of professional occupations has undergone significant change via changes in the credentials of both recent entrants and incumbent workers. Most notably, the credentials of those working in the teaching and nursing professions have changed from predominantly certificates and diplomas to 
university bachelor's degrees and above. This change may well have kept down measures of the average earnings of all bachelors degree holders over the period, particularly for females.

To investigate this credential changes based explanation of earnings premia trends, we construct an estimate of the potential effect that these changes in credentials may have had on movements in the estimated education earnings premia in Australia over time. This construction is based on the assumption that these changes in credentials have not altered the relative wages of those working in those particular occupations. We provide several pieces of evidence to support the assumptions employed in the construction of the estimated effect of credential changes on earnings premia trends.

To preview our results, we find that the observed earnings premium paid to bachelors degree holders and above has remained remarkably stable from 1981/82 to 2003/04 for males, and has fallen slightly for females. The premium paid to diploma holders has fallen considerably over the period, while the premium paid to certificate holders has also remained quite stable for males, and fallen for females. Finally, the results of our investigation of the effect of changes in credentials suggest that these changes may potentially have kept down measured education earnings premia by up to six percentage points for females, but only by a small amount for males.

The outline for the remainder of the paper is as follows. A discussion of some of the related literature is provided in Section 2. Details of the expansion of higher education in Australia are provided in Section 3. Estimates of education earnings premia over time are presented in Section 4. Our estimates of the potential effect of education credential relabelling on measured education earnings premia are presented in Section 5. Some concluding remarks are provided in Section 6, including a short discussion of other potential explanations for why education premia have not increased in Australia as they appear to have in the US.

\section{The Related Literature}

A number of studies have investigated changes over time in education earnings differentials in Australia. These include Miller (1984), Chia (1991), Maglen (1991, 1994), Karmel (1994, 
1995a, 1995b), Gregory (1995), Borland (1996, 1999), and Neville and Saunders (1998). The majority of these studies use information from the Australian Bureau of Statistics (ABS) household income surveys for various years, starting in 1968/69, and reaching as recently as 1994/95 in the case of Borland (1999). These studies show a trend decline in education earnings premia for individuals with post-secondary education from 1968/69 to the early to mid 1980s. There is some evidence of recovery in premia from the mid 1980s to the end of the 1980s, but overall premia are quite stable in the 1980s to the mid 1990s. In Section 4, we update these measures of education earnings premia to 2003/04, using both the income surveys and data from the Australian Censuses conducted from 1981 to 2001.

Although there is broad agreement regarding this overall trend, individual studies identify or consider further particular aspects of the changes. Miller (1984), producing internal rates of return (IRR) estimates using three income survey data sets between 1968/69 to 1978/79, showed that there were large declines in the earnings premium for prime age (25 to 54) male degree holders over this period, but essentially no decline for young workers (15 to 24). Miller suggests this raises a puzzle for standard supply and demand explanations for the decline in returns to education. Supply of educated workers increased significantly over this period, so one would expect that such an increase would have most effect on the starting salaries of young workers. Chia (1991) extended Miller's (1984) analysis up to 1985/86, finding that the education premium for young workers (15 to 24 ) continued to remained stable up until 1985/86, while the premium for older workers continued to decline, particularly those aged 25 to 44. Maglen (1991) focuses on the effect of the education expansion on earnings inequality, and in so doing extends IRR estimates of Miller and Chia up until 1989/90.

Gregory (1995) documents education earnings premia separately by age group and gender over the $1968 / 69$ to $1989 / 90$ period and speculates on the reasons for the large increase in education levels over the period, despite reductions in the earnings returns to education. He argues that the loss of full time jobs over the period, particularly for young, old and unskilled males can explain the education expansion, with more individuals undertaking further study, not for the higher earnings, but for the higher probability of gaining full-time employment. Borland (1996), 
considering the same time period, investigates the roles of supply and demand in determining the observed trends in premia, employing the estimation framework of Katz and Murphy (1992). Large increases in supply of educated workers were found to have put downward pressure on earnings premia over the whole period for females, and during the 1970s in the case of males. His estimation results also suggest that there has also been significant increases in demand for educated workers over the period, and indeed the premium for young workers (15 to 24) actually increased over the 1980s for males. Neville and Saunders (1998) consider differences by sector of employment, showing that premia have risen over the 1980s for private sector employees, but fallen for public sector employees. The authors argue that the consequence of looking at the two groups of employees together is that increases in education earnings premia for private sector employees were masked.

In addition to the studies documenting trends in education earnings premia over time in Australia, several studies have focussed on estimating the returns to education in Australia at a point in time. Often these studies take into account not only earnings levels, but also tax rates, forgone earnings while studying, tuition fees and employment probabilities over the course of the working life. Examples are Chapman and Chia (1989), Chapman and Salvage (1997), Borland et al (2000), Borland (2002), Ryan (2002), and Colegrave (2006). Both Borland et al (2000) and Ryan (2002) provide a survey of a number of prior studies along these lines. They also summarise studies that estimated Mincer type wage regressions, which produce premia estimates controlling for other factors that affect earnings such as age or work experience. We employ such techniques below when constructing our own estimates.

Borland et al (2000) additionally set out the main difficulties in estimating the returns to education, and the various methods that have been employed by Australian researchers to overcome some of these difficulties. The key difficulty for studies estimating the return to education is determining the counterfactual outcomes for individuals who invest in a higher level of education, and for those who do not. A common approach is to assume the less-educated provide the counterfactual for the more-educated, and the more-educated provide the counterfactual for the less-educated. In other words, the difference in observed average earnings profiles between 
more and less educated individuals is entirely attributed to educational attainment differences. The concern is that the two groups of individuals may not be directly comparable. The standard critique is that those who chose to invest in higher education may have higher levels of ability, and would thus have earned more than those who did not invest even if they themselves did not invest. If this is the case, the estimated wage profiles will suffer from endogeneity or "ability" bias. A number of researchers attempting to estimate the returns to education have dealt with this potential bias issue by assuming that only a proportion of the difference in wages between those with post-secondary education and those without is attributable to the education itself. Referred to by Norris et al, 2005, p. 75 as the 'alpha coefficient', this proportion has been set at levels between two thirds and one in various studies.

Rather than assume the causal effect of education on earnings, as the alpha coefficient technique in essence does, a small number of Australian studies have attempted to estimate the causal effect. Miller et al $(1995,2005)$ employ samples of twins to estimate the causal effect of education on earnings. They argue that identical twins should have the same genetic ability and family background, so any systematic differences in earnings across twins with different levels of education should reflect causal effects. Leigh and Ryan (2007) employ instrumental variable techniques to estimate causal effects, using school leaving laws and month of birth as instruments for education. Both of these studies find that estimates change very little when using such techniques compared with using standard regression techniques, implying ability bias in estimates of education earnings premia is small.

In the analysis below, our primary concern is not with estimation of the causal return to education. We are instead interested in investigating over time trends in the observed association between education and earnings. These trends should correspondingly be interpreted with caution, since they may not reflect trends in the causal effect of education on earnings. 


\section{The Australian Higher Education System}

There has been a significant expansion of the Australian higher education system over the past four decades. It has also undergone some significant changes, the most notable being the move from a binary system to the Unified National System (UNS) in the late 1980s and early 1990s, and the introduction of the Higher Education Contribution Scheme (HECS) in 1989. The binary system distinguished universities from Colleges of Advanced Education (CAEs), which were more vocationally oriented and did not conduct research. Under the Unified National System, which began to be implemented in the late 1980s, all higher education institutions were treated in the same manner. TAFE institutions, offering lower-level vocational training, continued under the new system. Immediately preceding the phasing in of the UNS, Australia had 19 universities and 46 CAEs. By 1993, following a number of amalgamations and transformations of CAEs into universities, there were no CAEs and 38 universities (37 public and 1 private). Currently, there are 39 universities, two of which are private.

The expansion in the number of students enrolled in the higher education system has been substantial. Table 1 provides details. University enrolment numbers grew steadily from 1966 to 1976, but the rate of growth slowed between 1976 and 1986. However, growth in total higher education enrolments over this period was in fact very strong, with Colleges of Advanced Education (CAE's) being the major source of growth. CAE's were first established in 1967. Their growth was such that CAE enrolments exceeded university enrolments by 1982, and their enrolment growth continued to outpace that of universities up until around 1990, when CAE's were transformed into universities, via amalgamation and absorption into existing universities in some cases.

Overall higher education student numbers in 2006 were over ten times what they were in 1966. If we exclude overseas students from the 2006 figures, and assume no overseas students in 1966, the growth has still been over seven hundred percent. To put this in perspective, domestic student numbers were $3.52 \%$ of the overall Australian population in 2006, but were only $0.78 \%$ of the population in 1966. Note also the change in the composition of enrolment within the higher 
education sector over the period. The proportion of "Other" enrolments (primarily diplomas) in the total grew from 8 percent in 1966 to 35 percent in 1976. This proportion has subsequently shrunk to 12 percent in 2006. This change in large part reflects the shift in teacher education from diplomas to bachelors degrees and higher over the period. Note also that nursing students have been slowly included in these higher education statistics over the period from 1985 to 1993, as their education was moved out of hospitals and into higher education institutions, and positioned at the bachelors level.

The rising education levels of individuals aged between 25 and 59 can be seen in Figure 1, which draws on the the 1981 to 2001 Australian Censuses. The proportion of males holding a bachelors degree or higher rose from 8 to 18 percent over the 1981 to 2001 period. The increase was even larger among male full-time workers, growing from 9 to 22 percent. The proportion of males holding certificates remained constant at around 30 percent, while the proportion holding diplomas rose by 3 percentage points over the period. The corollary of the increase in degrees and diplomas was the large decline in the proportion of males with no post-secondary qualifications of 13 percentage points for all males, and 16 percentage points for male full-time workers. The larger decline among full-time workers reflects both rapidly declining labour force participation and an increasing prevalence of part-time work for this low educational attainment group. This decline was even more marked during the 1970s (Gregory, 1995). See also Borland, Gregory and Sheehan (2001), and Kennedy and Hedley (2003) for details of this phenomenon.

The increase in the educational attainment for females has been even larger than that for males (right hand side of Figure 1). The proportion of females aged 25 to 59 holding a bachelors degree or higher increased from 4 to 21 percent over the 1981 to 2001 period, while among full-time workers the increase was from 8 to 31 percent. The proportion of females with a highest qualification of a certificate or diploma rose from 18 to 21 percent, while among fulltime workers the proportion actually fell from 25 to 23 percent. ${ }^{1}$ Females without post-secondary

\footnotetext{
${ }^{1}$ There is a significant shift in those holding a certificate to those holding a diploma between the 1986 Census and the 1991 Census. This is in large part attributable to a change by the Australian Bureau of Statistics (ABS) in the classification of nursing education. The general classification of the standard certificate earned by individuals obtaining the qualifications for becoming a registered nurse while studying within a hospital changed with the adoption of the ABS Classification of Qualifications (ABSCQ) in the 1991 Census of Population and Housing
} 
Table 1: Student Enrolment in Higher Education in Australia (in thousands)

\begin{tabular}{|c|c|c|c|c|c|c|c|c|c|}
\hline & 1966 & 1971 & 1976 & 1981 & 1986 & 1991 & 1996 & 2001 & 2006 \\
\hline \multicolumn{10}{|l|}{ Universities } \\
\hline Higher degree & 7.6 & 12.5 & 17.6 & 21.8 & 25.4 & & & & \\
\hline Bachelor's degree & 76.5 & 102.6 & 124.6 & 132.4 & 142.2 & & & & \\
\hline Other & 7.3 & 8.7 & 11.8 & 12.4 & 13.9 & & & & \\
\hline Total & 91.3 & 123.8 & 154.0 & 166.6 & 181.5 & & & & \\
\hline Part-time \% & 33 & 36 & 35 & 40 & 39 & & & & \\
\hline \multicolumn{10}{|l|}{ CAEs } \\
\hline Higher degree & - & 0.0 & 0.4 & 1.1 & 2.5 & & & & \\
\hline Bachelor's degree & - & 9.0 & 46.2 & 87.9 & 116.9 & & & & \\
\hline Other & - & 36.1 & 88.0 & 76.0 & 89.8 & & & & \\
\hline Total & - & 45.1 & 134.6 & 165.1 & 209.2 & & & & \\
\hline Part-time \% & - & 55 & 54 & 54 & 50 & & & & \\
\hline \multicolumn{10}{|l|}{ Higher education } \\
\hline Higher degree & 7.6 & 12.5 & 18.0 & 23.0 & 27.9 & 44.3 & 78.9 & 107.8 & 200.0 \\
\hline Bachelor's degree & 76.5 & 111.7 & 170.8 & 220.3 & 259.1 & 380.6 & 474.8 & 543.1 & 669.8 \\
\hline Other & 7.3 & 44.8 & 99.8 & 88.4 & 103.7 & 109.7 & 80.4 & 75.5 & 114.4 \\
\hline Total & 91.3 & 168.9 & 288.6 & 331.7 & 390.7 & 534.5 & 634.1 & 726.4 & 984.1 \\
\hline Part-time $\%$ & 33 & 41 & 44 & 47 & 45 & 39 & 41 & 32 & 33 \\
\hline \multicolumn{10}{|l|}{ Overseas students } \\
\hline Number & $\mathrm{n} / \mathrm{a}$ & $\mathrm{n} / \mathrm{a}$ & $\mathrm{n} / \mathrm{a}$ & $\mathrm{n} / \mathrm{a}$ & 16.8 & 29.6 & 53.2 & 112.3 & 250.8 \\
\hline$\%$ of all students & & & & & 4 & 6 & 8 & 15 & 25 \\
\hline \multicolumn{10}{|l|}{ Domestic students } \\
\hline Number & $91.3^{a}$ & $168.9^{a}$ & $288.6^{a}$ & $331.7^{a}$ & 373.9 & 504.9 & 580.9 & 614.1 & 733.4 \\
\hline$\%$ of population & $0.78^{a}$ & $1.28^{a}$ & $2.05^{a}$ & $2.20^{a}$ & 2.32 & 2.90 & 3.15 & 3.14 & 3.52 \\
\hline
\end{tabular}

Notes: ${ }^{a}$ Assumes no overseas students for these years, as data on overseas student numbers were unavailable. Nursing students slowly included in statistics over the 1985 to 1993 period. 'Other' comprises postgraduate diplomas, graduate certificates, associate degrees, diplomas, non-award courses and miscellaneous other courses. In 1971, course-level composition of CAE enrolments estimated based on 1973 data contained in Commission on Advanced Education (1976). CAEs were first formed in 1967. For data sources, see Appendix A. 
qualifications showed a large decline (19 percentage points), which was again larger among fulltime workers (22 percentage points).

An interesting feature of the growth in educational attainment over the past several decades is that growth has not been confined to new labour market entrants. A significant proportion of individuals, particularly females, have undertaken bachelors degree or higher studies in their thirties and fourties. Figure 2 provides evidence of this phenomenon, presenting age profiles of the proportion of individuals with bachelors degrees or higher by birth cohort. The profiles are higher for more recent cohorts, indicating - as expected - that younger cohorts are more educated than older ones. The profiles are also upward sloping, reflecting increases in educational attainment within cohorts over time, particularly for females. ${ }^{2}$

Another notable change to the higher education system in Australia over the period we examine relates to nursing education. Prior to 1984 , nursing education was provided within hospitals. In August 1984, the Commonwealth government gave in-principal support to the transfer of registered nurse education to the higher education sector. The transfer was staggered over the 1985 to 1993 period, occurring in each Australian State according to its own timetable. By 1994, all registered nursing education was located in universities as an undergraduate degree program. ${ }^{3}$

\section{Education Earnings Premia Estimates}

We provide estimates of the average earnings premia of post-secondary educated workers over time using two series of data collections. The first comprises the ABS household income surveys conducted between 1982 and 2004. The income surveys are the most common data source for studies of earnings outcomes by education level in Australia. The second series of data comprise the Censuses of Population and Housing conducted between 1981 and 2001. The census data provide a check on the income surveys estimates. Each data series has its benefits and limitations,

(ABS, 1993). Prior to 1991, the qualification was deemed to be an "other" certificate (as opposed to a "trade" certificate) by the ABS, while from 1991 it was deemed to be at the level of an undergraduate diploma.

${ }^{2}$ Increases in education levels within a cohort can be due to both adult education and to immigration of educated workers.

${ }^{3}$ See National Review of Nursing Education (2001) for further details. 
as discussed below. Despite the differences between the two series, they produce very consistent estimates of earnings premia by level of educational attainment.

\subsection{Income Surveys}

We begin by constructing estimates of education earnings premia over time using information taken from the Income Surveys. ${ }^{4}$ The main benefit of this data series over the Census data employed below is the reporting of employment income separately from other types of income, and the reporting of income in levels (continuous measure) rather than just in broad income categories.

The public-release Income Survey data files are used to produce cross-sectional estimates of the wage premia paid to post-secondary educated workers using the following Mincerian wage equation:

$$
\begin{aligned}
E[\ln (w)]=\beta_{0}+\beta_{1} D E G+\beta_{2} O P S & +\beta_{3} A 30 \_34+\beta_{4} A 35 \_39+\beta_{5} A 40 \_44 \\
& +\beta_{6} A 45 \_49+\beta_{7} A 50 \_54+\beta_{8} A 55 \_59
\end{aligned}
$$

Two post-school education categories are distinguished: the first comprising workers holding a bachelor's degree or higher $(D E G)$, and the second comprising workers holding some other type of post-secondary education credential, usually a diploma or certificate $(O P S)$. The base education category comprises workers with no post-school qualifications. The coefficients on the education indicators $\left(\beta_{1}\right.$ and $\left.\beta_{2}\right)$ are thus interpreted as log wage premia relative to workers holding no post-secondary education credentials. The variables beginning with $A$ 's are five-year age group indicators, capturing a common age profile of earnings over an individual's working life.

A separate wage equation is estimated for each cross-section, facilitating description of the evolution of education earnings premia over time. We estimate these wage equations separately by gender, and focus on the results for the weekly wages of full-time employees aged from 25

\footnotetext{
${ }^{4}$ The Income Surveys have had several different names over the years. See Appendix A for details.
} 
to 59. ${ }^{5}$ Eleven Income Surveys have been conducted by the ABS over the period we examine, but the data sets for the surveys from 1994 to 2001 contain comparatively small samples. We therefore pool together consecutive-year data sets from 1994 onwards to increase the precision of our estimates, leaving us with seven sets of cross-sectional estimates. ${ }^{6}$ See Appendix A for details on the data sets pooled together and for further information about the income survey data.

The main estimates of education wage premia $\left(\hat{\beta}_{1}\right.$ and $\left.\hat{\beta}_{2}\right)$ are presented in Figures 3 and 4 for males and females respectively. The dashed lines in the figures denote 95 percent confidence intervals around the estimates. The premium earned by full-time employee males with a degree or higher over full-time employee males with no post-secondary credentials is quite stable over the 1982 to $2002-04$ period, at approximately $0.42 \log$ points. This equates to a 52 per cent wage premium. ${ }^{7}$ The wage premium earned by male employees with other post-secondary credentials (diplomas and certificates) is also quite stable over the period at $0.12 \log$ points (13 per cent). For females, there is evidence of a decline in education wage premia over the 1982 to 2002-04 period. The premium earned by female holders of degrees or higher fell from around 0.46 to 0.40 $\log$ points (from 58 to 49 per cent). For females holding certificates or diplomas, the decline is larger, from 0.19 to $0.07 \log$ points (21 to 8 per cent). ${ }^{8}$

\subsection{Census Data}

We now estimate education income premia using information on individuals taken from the one percent sample Confidentialised Unit Record Files (CURFs) of the Australian Census of Population and Housing. Two main benefits of this data source over the Income Surveys employed above are: (i) more detailed reporting of levels of post-secondary education, and (ii) larger sample sizes. The earnings variable is, however, total income from all sources rather than being confined to labour earnings only. An additional limitation of the income variable is that it is

\footnotetext{
${ }^{5}$ Hours worked information is recorded in quite coarse categories in the 1982 income survey in particular, making the construction of accurate hourly earnings measures for all workers difficult.

${ }^{6}$ For the pooled samples, an indicator of survey year is also included in the estimated regressions.

${ }^{7}$ The log difference $l d$ is transformed into a percentage difference $p d$ using the following standard calculation: $p d=100\left(e^{l d}-1\right)$.

${ }^{8}$ Parameter estimates for the age indicators, capturing the earnings profile over a worker's lifetime, are not reported, but are available upon request.
} 
grouped into 8 to 14 income categories, depending on the Census year. We construct a "continuous" measure of income using midpoints within each reported income category. Refer to Appendix A for further details on this data source and how we employed the data from it in our analysis.

Estimates of education income premia using the Census data are presented in Figures 5 and 6 for males and females respectively. The dashed lines in the figures again denote 95 percent confidence intervals around the estimates. As with the estimates constructed using the Income Survey data above, the premia were estimated via log income regressions of the form of Equation 1, but in this case indicators for four separate post-secondary education categories were included rather than just two. The base education category is again workers with no post-school qualifications, and equations are estimated using full-time employees aged 25-59 years. The same six age group indicators were included. Separate equations were estimated for males and females and for each of the five Censuses from 1981 to 2001.

The estimates using the Census data are generally consistent with those generated using the Income Surveys discussed above; thus, the conclusions drawn are robust to the choice of data source. The income premia received by male full-time employees holding bachelors degree and post-graduate credentials over male full-time employees with no post-secondary credentials has remained quite constant over these two decades. The bachelor degree holder income premium is constant at around $0.45 \log$ points (57 percent) and for post-graduate credential holders remains at around $0.52 \log$ points (68 percent). The income premium earned by male certificate holders has fallen slightly, while that earned by male diploma holders has fallen more considerably, from 0.40 to $0.30 \log$ points (49 to 35 percent). For female full-time employees, reductions in income premia for diploma and certificate holders are large over the period, while a small reduction is observed for bachelor degree holders. There is no obvious trend in the income premium of female post-graduate credential holders. 


\section{Credential Changes and Education Earnings Premia}

We now turn to our second objective: to investigate the hypothesis that the earnings premium of workers holding more "traditional" bachelor degrees may in fact have risen, but the rise has been masked by an expansion of the scope of bachelor degree education in Australia since the 1980s. We begin by illustrating the significant change in the education credentials held by fulltime employees in professional occupations, focussing on nurses and teachers in particular. We then construct an estimate of the potential effect that these changes in credentials may have had on overall estimated education earnings premia.

\subsection{Education Levels by Occupation}

The percentage of full-time employees with each type of education credential within each major (ASCO2 one digit level) occupation group are presented in Figure 7 for males and Figure 8 for females. These figures were constructed using data from the Australian Census. In constructing these figures, effort was made to ensure the major occupation groups were as consistent as possible across Census years, given the information provided in the confidentialised public-use Census files. Mapping the 1981 occupations into professional and associate professional groups was particularly problematic, resulting in some difficulties in comparing the figures for 1981 with other Census years. See Appendix A for details.

Observe the significant changes in the level of education credentials held by workers in each of the major occupation groups over the period. There has been a small increase in the proportion of workers with any post-secondary education credential in all of the less skilled occupations. The most significant change is the large increase in the proportion of workers in professional occupations with bachelor degrees or above, with a matching decrease in the proportion with certificates and diplomas. For males, the proportion with bachelor degrees or above has increased from 40 percent in 1981 to 65 percent in 2001, while for females the increase is from 22 percent to 70 percent over the same period. There has also been a significant increase in the proportion of managers holding bachelor degrees or higher, but no offsetting decline in the proportion holding 
diplomas and certificates.

This general increase in the education credentials of workers may have a number of causes. It may be due to up-skilling, reflecting increased skill requirements of jobs. The increase may also reflect increasing levels of over-education of workers in the labour market, as individuals find it more difficult to obtain a job that uses their education fully as overall levels of education in the market increase. A third possibility is that it reflects changes in the labelling of credentials in certain important cases. What was labelled a certificate or diploma provided by a non-university higher education institution under the former binary system is now labelled a bachelor degree provided by a university under the Unified National System introduced at the end of the 1980s. We argue that this final explanation may have led to some of the observed stability in estimated education earnings premia in Australia.

Two large professional occupations in particular that have undergone a major change in the credentials held by workers are nursing and teaching. These changes can be observed in Table 2 . The credential held by the majority of registered nurses was a certificate up until 1986, and then in 1991 was relabelled a diploma by the Australian Bureau of Statistics when it adopted its new ABS Classification of Qualifications (ABSCQ, see ABS, 1993). Since the early to mid 1980s, nursing education has shifted from being provided in hospitals directly to being provided by universities. Most newly qualified nurses now hold a bachelor degree or higher. ${ }^{9}$ This change is very important for female employees overall, as nursing comprised about 4 percent of the female full-time workforce in 2006. This change is less important for males, with nursing comprising only 0.4 percent of male full-time employee occupations in 2006.

A significant change in the credentials held by those working in the teaching profession has also occurred. In 1981, school teachers were predominantly holders of a diploma that was granted by a College of Advanced Education (CAE), particularly for females. More recently, teacher education has been provided predominantly by the new generation universities, which were transformed from teachers colleges (CAEs) after the reforms of Higher Education in the

\footnotetext{
${ }^{9}$ This shift of nursing education from diplomas and certificates to bachelor degrees occurred over the 1980s and 1990s in Canada, the 1990s in the United Kingdom, and is changing slowly in the United States also.
} 
Table 2: Percentage of Nurses and Teachers with Each Education Credential

\begin{tabular}{|c|c|c|c|c|c|c|}
\hline & 1981 & 1986 & 1991 & 1996 & 2001 & 2006 \\
\hline \multicolumn{7}{|l|}{ Male Nurses } \\
\hline None & 10 & 19 & 3 & 6 & 5 & 4 \\
\hline Certificate & 81 & 73 & 4 & 5 & 6 & 7 \\
\hline Diploma & 7 & 5 & 78 & 52 & 24 & 20 \\
\hline Bachelors & 3 & 4 & 13 & 31 & 53 & 55 \\
\hline Post-graduate & 1 & 0 & 3 & 6 & 12 & 14 \\
\hline$\%$ of all employees & 0.28 & 0.34 & 0.47 & 0.32 & 0.39 & 0.43 \\
\hline \multicolumn{7}{|l|}{ Male Teachers } \\
\hline None & 2 & 2 & 1 & 2 & 2 & 1 \\
\hline Certificate & 2 & 2 & 1 & 1 & 1 & 0 \\
\hline Diploma & 42 & 38 & 23 & 15 & 12 & 8 \\
\hline Bachelors & 30 & 41 & 50 & 52 & 60 & 64 \\
\hline Post-graduate & 24 & 17 & 25 & 30 & 26 & 27 \\
\hline$\%$ of all employees & 2.20 & 1.93 & 2.45 & 2.20 & 2.37 & 2.36 \\
\hline \multicolumn{7}{|l|}{ Female Nurses } \\
\hline None & 8 & 14 & 4 & 6 & 6 & 4 \\
\hline Certificate & 85 & 81 & 4 & 5 & 6 & 8 \\
\hline Diploma & 6 & 2 & 74 & 47 & 21 & 19 \\
\hline Bachelors & 1 & 2 & 17 & 36 & 56 & 56 \\
\hline Post-graduate & 0 & 1 & 1 & 5 & 11 & 13 \\
\hline$\%$ of all employees & 7.30 & 5.74 & 5.20 & 4.29 & 4.08 & 4.03 \\
\hline \multicolumn{7}{|l|}{ Female Teachers } \\
\hline None & 4 & 2 & 2 & 2 & 2 & 1 \\
\hline Certificate & 2 & 1 & 0 & 0 & 0 & 0 \\
\hline Diploma & 61 & 56 & 37 & 25 & 19 & 14 \\
\hline Bachelors & 16 & 25 & 38 & 45 & 55 & 61 \\
\hline Post-graduate & 17 & 16 & 23 & 27 & 24 & 24 \\
\hline$\%$ of all employees & 7.69 & 6.04 & 7.47 & 8.13 & 8.39 & 8.23 \\
\hline
\end{tabular}

Notes: Source: Australian Censuses of Population and Housing. Figures for 1981, 1996, 2001 and 2006 were constructed from tabulations provided directly by the ABS. Figures for 1986 and 1991 were constructed from the public-use one percent samples. The population comprises full-time employees only. "Nurses"" are registered nurses only. "Teachers" are school teachers only. 
late 1980s and early 1990s. A proportion of teachers trained under the former system have since updated their credentials, with many earning post-graduate certificates or diplomas. Note how important the teaching profession is for females, with 8 percent of all female full-time employees working as school teachers. Again the significance of this change is much smaller for males, since just over 2 percent of male full-time employees are employed as school teachers.

\subsection{Potential Effect of Credential Relabelling}

Potential relabelling of education credentials among professional workers could have held down the average estimated earnings of bachelor degree, diploma and certificate holders simultaneously. The intuition for this process is illustrated by the following simple scenario. Suppose that a particular group of professional workers (say nurses) were among the highest paid of all workers holding a certificate at the start of the period. These same workers were, however, paid less than the average wage of "traditional" bachelor degree holders. A subsequent shift of these workers from the certificate category to the bachelor degree category would, ceteris paribus, lower the overall average wages of both certificate holders and bachelor degree holders.

Our approach to constructing an estimate of the potential effect of credential relabelling on education earnings premia is as follows. Overall education premia can be viewed as weighted averages of education premia within each occupation, with each occupation carrying a weight equal to its share of the workforce. Counterfactual education premia that reflect the education premia that would have occurred if potential credential relabelling had not occurred can be constructed by appropriate re-weighting of the data. This construction is undertaken in four stages. First, we produce estimates of education premia within each occupation group. Second, we provide an estimate of the extent of credential relabelling that we believe has occurred within each occupation group. Third, we produce estimates of the education premia by occupation group that would have prevailed in the absence of any such relabelling. Fourth, we construct new estimates of education premia averaged across all occupations using the counterfactual premia by occupation group and counterfactual weights under the hypothesis of no credential relabelling. The overall effect of relabelling on aggregate education earnings premia is then calculated as the dif- 
ference between the observed premia and the counterfactual premia. We provide details on how we identify within-occupation group credential relabelling and its effect on within-occupation group education earnings premia below.

\subsubsection{Education Premia Within Occupation Groups}

Our first step is to estimate actual education earnings premia of full-time employees separately by major occupation group. We calculate these premia for the period 2002-04. These calculations provide baseline estimates of actual education earnings premia for each occupation group in 2002-04 in the presence of credential relabelling. We focus our discussion on analysis that draws on the Income Surveys, given the advantages of this data in terms of reporting a continuous earnings measure and separately identifying employment income.

Estimates of education earnings premia for each occupation group are presented in the top panels of Tables 3 and 4 for males and females respectively. The estimates are relative to the base case of a labourer with no post-secondary qualifications. Note that within major occupation groups (reading across rows), earnings mostly have the expected ordering by education credential. Of most interest here, we observe that full-time employees in professional occupations who hold a certificate or diploma (other post-secondary) earn considerably less on average than those holding a bachelor degree or higher in professional occupations. The difference of $0.178 \log$ points $(0.570$ minus 0.392$)$ for females implies bachelor degree holders earn approximately 19 percent more than the other post-secondary group. Also of importance is that other post-secondary credential holders in professional occupations earn more than employees who also hold other post-secondary credentials but work in less skilled occupations (reading down the column).

If there has been a re-allocation of workers within the professional occupation group from the education level of other post-secondary to the level of bachelor degrees and above, it may have acted to reduce the average earnings of both degree holders and holders of other post-secondary qualifications. Holders of other post-secondary qualifications in professional occupations are paid more than such holders in all other major occupation groups other than managers. Remov- 
Table 3: Estimates of Male Occupation-by-Education Earnings Premia

\begin{tabular}{lcccccc}
\hline \hline & $\begin{array}{c}\text { Degree } \\
\text { plus }\end{array}$ & $\begin{array}{c}\text { Other } \\
\text { post-sec. }\end{array}$ & $\begin{array}{c}\text { No } \\
\text { post-sec. }\end{array}$ & $\begin{array}{c}\text { Degree } \\
\text { plus }\end{array}$ & $\begin{array}{c}\text { Other } \\
\text { post-sec. }\end{array}$ & $\begin{array}{c}\text { No } \\
\text { post-sec. }\end{array}$ \\
\hline Premia & & & & & $2002-04$ & \\
Managers & & & & $0.889^{c}$ & $0.501^{c}$ & $0.467^{c}$ \\
Professionals & & & & $0.679^{c}$ & $0.542^{c}$ & $0.480^{c}$ \\
Ass. Prof. & & & & $0.623^{c}$ & $0.426^{c}$ & $0.298^{c}$ \\
Trades & & & & $0.441^{c}$ & $0.325^{c}$ & $0.216^{c}$ \\
Clerical & & & & $0.378^{c}$ & $0.285^{c}$ & $0.248^{c}$ \\
Int. Prodn. & & & & $0.229^{c}$ & $0.312^{c}$ & $0.240^{c}$ \\
Elem. Cler. & & & & 0.177 & 0.074 & $0.086^{a}$ \\
Labourers & & & & 0.099 & $0.151^{c}$ & base \\
\hline Weights & & 1986 & & & 2001 & \\
Managers & 2.050 & 3.470 & 3.840 & 4.520 & 3.740 & 3.770 \\
Professionals & 7.690 & 5.470 & 2.100 & 12.380 & 4.070 & 2.400 \\
Ass. Prof. & 0.660 & 5.710 & 5.020 & 2.430 & 6.450 & 4.830 \\
Trades & 0.130 & 15.050 & 5.420 & 0.430 & 13.910 & 4.570 \\
Clerical & 0.690 & 2.350 & 8.630 & 1.380 & 3.460 & 5.980 \\
Int. Prodn. & 0.050 & 2.340 & 10.620 & 0.260 & 3.520 & 10.060 \\
Elem. Cler. & 0.100 & 0.750 & 3.150 & 0.300 & 1.050 & 2.570 \\
Labourers & 0.070 & 2.340 & 12.280 & 0.150 & 1.960 & 5.820 \\
\hline \hline
\end{tabular}

Notes: Premia estimates are obtained from the pooled 2002-3 and 2003-04 income surveys and are for occupation-education interaction terms in log weekly earnings regressions estimated on full-time employees aged 25 to 59. Regressions also include five-year age group indicators, a marital status indicator and indicators for quarter and year of survey. $a, b$ and $c$ denote statistical significance at the 10, 5 and 1 percent levels respectively. Sample size is 8,143 in 2002-4. Weights are obtained from the 1986 and 2001 Censuses and are the percentage of all full-time employees aged 25 to 59 in each occupation-by-education cell. Sample size is 23,539 in 1986 and 25,176 in 2001. The Clerical occupation group comprises Intermediate Clerical and Advanced Clerical. 
Table 4: Estimates of Female Occupation-by-Education Earnings Premia

\begin{tabular}{lcccccc}
\hline \hline & $\begin{array}{c}\text { Degree } \\
\text { plus }\end{array}$ & $\begin{array}{c}\text { Other } \\
\text { post-sec. }\end{array}$ & $\begin{array}{c}\text { No } \\
\text { post-sec. }\end{array}$ & $\begin{array}{c}\text { Degree } \\
\text { plus }\end{array}$ & $\begin{array}{c}\text { Other } \\
\text { post-sec. }\end{array}$ & $\begin{array}{c}\text { No } \\
\text { post-sec. }\end{array}$ \\
\hline Premia & & & & & $2002-04$ & \\
Managers & & & & $0.760^{c}$ & $0.394^{c}$ & $0.444^{c}$ \\
Professionals & & & & $0.570^{c}$ & $0.392^{c}$ & $0.342^{c}$ \\
Ass. Prof. & & & & $0.466^{c}$ & $0.260^{c}$ & $0.203^{c}$ \\
Trades & & & & 0.180 & $0.161^{b}$ & $0.152^{c}$ \\
Clerical & & & & $0.200^{c}$ & $0.093^{c}$ & $0.121^{c}$ \\
Int. Prodn. & & & & 0.137 & $0.240^{c}$ & 0.002 \\
Elem. Cler. & & & & -0.117 & 0.035 & -0.069 \\
Labourers & & & & 0.077 & 0.008 & base \\
\hline Weights & & 1986 & & & 2001 & \\
Managers & 0.97 & 0.91 & 1.29 & 4.11 & 1.45 & 2.24 \\
Professionals & 8.92 & 12.80 & 2.40 & 20.46 & 5.71 & 3.14 \\
Ass. Prof. & 0.57 & 2.06 & 3.15 & 2.66 & 4.31 & 7.11 \\
Trades & 0.04 & 0.72 & 1.63 & 0.16 & 0.89 & 1.01 \\
Clerical & 1.17 & 8.27 & 26.34 & 3.29 & 8.34 & 20.25 \\
Int. Prodn. & 0.00 & 0.45 & 4.94 & 0.07 & 0.28 & 2.47 \\
Elem. Cler. & 0.14 & 1.79 & 8.96 & 0.47 & 1.21 & $4.92^{c}$ \\
Labourers & 0.08 & 0.91 & 11.50 & 0.23 & 0.51 & 4.70 \\
\hline \hline
\end{tabular}

Notes: Premia estimates are obtained from the pooled 2002-3 and 2003-04 income surveys and are for occupation-education interaction terms in log weekly earnings regressions estimated on full-time employees aged 25 to 59. Regressions also include five-year age group indicators, a marital status indicator and indicators for quarter and year of survey. $a, b$ and $c$ denote statistical significance at the 10, 5 and 1 percent levels respectively. Sample size is 4,571 in 2002-4. Weights are obtained from the 1986 and 2001 Censuses and are the percentage of all full-time employees aged 25 to 59 in each occupation-by-education cell. Sample size is 11,043 in 1986 and 14,768 in 2001. The Clerical occupation group comprises Intermediate Clerical and Advanced Clerical. 
ing a large number of such workers from the professional occupation group will thus lower the average earnings of all remaining other post-secondary qualification holders. These same other post-secondary qualification holders are paid less than bachelor or above holders in the professional occupations. Including such workers now in the degree plus education category may also have lowered the average income of all bachelor degree holders.

\subsubsection{Extent of Credential Relabelling}

The second step is to estimate the extent or scale of potential credential relabelling over time. Our estimate of the extent or scale of credential relabelling uses the following assumption.

\section{Assumption 1:}

The growth in the proportion of workers holding bachelor degrees and higher within the professional occupation group between 1986 and 2001 reflects relabelling of certificates and diplomas only.

The weights provided in the lower panels of Tables 3 and 4 are full-time employment shares of each education by occupation group and were constructed using Australian Census data for 1986 and 2001. The Census is used in preference to the Income Surveys to construct these weights because the public use files of the Income Surveys only provide one-digit level occupation categories that are too aggregated to allow us to construct consistent occupation categories across sample years. We also chose not to use the 1981 Census for weights information given additional problems in allocating the individual occupations provided in the 1981 Census public use files to the ASCO2 major occupation groups provided in 2001. See Appendix A for details about how we constructed consistent major occupation categories using the Census.

Looking now at these weights, observe that the proportion of all female full-time employees that work in professional occupations and hold an other post-secondary qualification fell from 12.8 percent to 5.71 percent between 1986 and 2001 . The proportion that work in professional occupations and hold a bachelor degree or higher increased significantly over the same period, from 8.92 to 20.46 percent. Changes in the same directions are observed for males, but on smaller scales. Assumption 1 essentially claims that the reallocation of professional workers 
between education categories is entirely due to relabelling. Note also that Assumption 1 implies that there has not been any relabelling in any other occupation group.

Assumption 1 suggests that the underlying skill composition of workers in professional occupations has remained essentially unchanged between 1986 and 2001. Even if the changes in education levels reflect increased skills, but workers are not rewarded for their increased skill levels with higher earnings, our calculations of the effect of credential changes on estimates of education earnings premia are still valid. It is possible that some of the growth in the education levels of professional employees over the period may result in higher earnings for those particular workers earning higher credentials, so our estimate of the potential effect of relabelling can be thought of as an upper bound.

To check whether Assumption 1 is defensible, we examined whether the relative wages of nurses and teachers have increased over the 1986 to 2004 period as their average levels of education have increased. To do this, we use published data derived from ABS employer surveys on average weekly earnings by detailed ASCO1 and ASCO2 two digit level occupation. ${ }^{10}$ Occupation level wages are available for all adult full-time non-managerial employees separately by gender. Age and education levels of employees cannot, however, be ascertained from this data source.

Figures 9 through 12 present average wages of nurses and teachers relative to average wages of all employees in three high skill one digit occupation groups: professionals, para/associate professionals, and tradespersons. The break in the middle of the figures marks the change in the ABS occupational classification scheme from ASCO1 to ASCO2 in the mid-1990s. The unambiguous conclusion to be reached from these figures is that, apart from nurses in the late 1980s, the wages of nurses and teachers have remained remarkably stable relative to other employees in skilled occupations. The relative wages of male teachers may actually have fallen over the period. The general increase in the education credentials held by nurses and teachers has thus not

\footnotetext{
${ }^{10}$ Wages by detailed occupation are provided in the ABS releases Employee Earnings and Hours, Australia, catalogue number 6306.0. This release has also been called Distribution and Composition of Employee Earnings and Hours, Australia in some years. This release was annual from 1978 until 1996, and has been released biannually since 1996.
} 
resulted in any real improvement in their relative earnings. Such workers may be more skilled, but this does not appear to have been translated into additional remuneration.

\subsubsection{Estimates of Education Premia by Occupation Group in Absence of Relabelling}

The third step is to construct counterfactual estimates of education premia by occupation group after essentially unwinding the relabelling of credentials that may have occurred. This construction of counterfactual estimates by occupation group employs a second assumption.

\section{Assumption 2:}

Employees whose credentials have been relabelled earn on average the same as those who have not had their credentials relabelled.

Assumption 2 implies that there is a proportion of bachelor degree holders working in professional occupations in 2001 that are assumed to have relabelled other post-secondary qualifications (diplomas and certificates). The holders of these relabelled qualifications are assumed to have average earnings equal to the average earnings of holders of non-relabelled other postsecondary qualifications who are working in professional occupations in 2001.

To ascertain whether this second assumption is defensible, we again provide details on the earnings of nurses and teachers. Using data drawn from the 2001 Census, Table 5 presents mean incomes by educational attainment within each of the two occupations. As before, we restrict our attention to full-time employees. The mean income of female nurses holding diplomas was $\$ 864$ per week, compared with $\$ 877$ for female nurses holding bachelor degrees, a mere 1.5 percent higher. For males, nurses holding diplomas actually earned on average 4 percent more than those holding bachelor degrees. For female teachers, diploma holders earned just 0.9 percent less than bachelor degree holders, while for male teachers, diploma holders earned around 1 percent more than bachelor degree holders. Teachers with postgraduate credentials earned around 1 percent (males) to 5 percent (females) more than diploma holders. Nurses with postgraduate credentials earned around 7 percent (males) to 13 percent (females) more than diploma holders. Thus, with the exception of nurses holding postgraduate credentials, the incomes of teachers and nurses are 
Table 5: Nursing and Teaching Weekly Income by Education Level - 2001

\begin{tabular}{lcccc}
\hline $\begin{array}{l}\text { Post-secondary } \\
\text { credentials }\end{array}$ & $\begin{array}{c}\text { Male } \\
\text { Nurses }\end{array}$ & $\begin{array}{c}\text { Male } \\
\text { Teachers }\end{array}$ & $\begin{array}{c}\text { Female } \\
\text { Nurses }\end{array}$ & $\begin{array}{c}\text { Female } \\
\text { Teachers }\end{array}$ \\
\hline None & $\$ 750$ & $\$ 984$ & $\$ 651$ & $\$ 875$ \\
Certificate & $\$ 777$ & $\$ 858$ & $\$ 650$ & $\$ 668$ \\
Diploma & $\$ 996$ & $\$ 1,083$ & $\$ 864$ & $\$ 970$ \\
Bachelors & $\$ 957$ & $\$ 1,072$ & $\$ 877$ & $\$ 978$ \\
Post-graduate & $\$ 1,065$ & $\$ 1,094$ & $\$ 976$ & $\$ 1,019$ \\
\hline \hline
\end{tabular}

Notes: The data was provided by the ABS in customised tables using information from the 2001 Australian Census. The figures denote total income rather than just employee earnings, and are for full-time employees aged 25 to 59 .

very similar across education categories. ${ }^{11}$

Using the two assumptions stated above, we re-calculate education earnings premia for 200204 after "unwinding" the assumed relabelling of education categories since 1986 . The observed earnings premium to a degree for professional employees in 2002-04 can be expressed as a weighted average of the premium for those with 'traditional' degrees and the premium for those with 'new' degrees:

$$
p_{d, 2}=\omega p_{t d, 2}^{*}+(1-\omega) p_{n d, 2}^{*}=\omega p_{t d, 2}^{*}+(1-\omega) p_{o, 2}
$$

In this equation, $p_{d, 2}$ is the observed premium for all degree holder professionals in 2002-04, $\omega$ is the proportion of degree-holding professionals in 2002-04 with traditional degrees, $p_{t d, 2}^{*}$ is the (unobserved) premium for 'traditional' degree holder professionals in 2002-04, $p_{n d, 2}^{*}$ is the (unobserved) premium for 'new' degree holder professionals, and $p_{o, 2}$ is the premium for holders of other post-secondary qualifications in professional occupations. Assumption 2 yields the second equality in Equation 2. That is, professionals with 'new' degrees are assumed to obtain the same average premium as professionals with non-degree post-secondary qualifications $\left(p_{n d, 2}^{*}=p_{o, 2}\right)$. Solving for the unobserved premium to 'traditional' degrees and rearranging

\footnotetext{
${ }^{11}$ Note that these comparisons do not control for potential differences in the age (work experience) of workers with each education level. The customised tables of earnings by education group for nurses and teachers obtained from the ABS did not include information on age.
} 
yields Equation 3.

$$
p_{t d, 2}^{*}=p_{d, 2}+\left(\frac{1}{\omega}-1\right)\left(p_{d, 2}-p_{o, 2}\right)
$$

As long as $p_{d, 2}>p_{o, 2}$ and $0<\omega<1$, our estimate for the premium to 'traditional' degrees will exceed the observed premium to all degree holders in 2002-04. To obtain an expression for $\omega$ as a function of observed quantities, we define $s_{d, 1}$ as the proportion of professionals in 1986 with a degree or higher, which by Assumption 1 is also the proportion of professionals in 2002-04 with 'traditional' degrees, and we define $s_{d, 2}$ as the proportion of professionals with degrees in 2002-04. Noting that $s_{d, 1}<s_{d, 2}$, we then define $\omega=s_{d, 1} / s_{d, 2}$. Using the shares in Table 4 for females, the value for $\omega$ is calculated as $0.37 / 0.70=0.53$. In other words, of all female professionals holding degrees or higher in 2002-04, 53 percent are assumed to hold 'traditional' degrees, while the rest are assumed to hold 'new' degrees.

Substituting this definition for $\omega$ into Equation 3 yields an estimate of the premium to a 'traditional' degree in 2002-04 as a function of observed quantities.

$$
p_{t d, 2}^{*}=p_{d, 2}+\left(\frac{s_{d, 2}}{s_{d, 1}}-1\right)\left(p_{d, 2}-p_{o, 2}\right)
$$

\subsubsection{Counterfactual Estimates of Education Premia Averaged over All Occupations}

Recall that our hypothetical exercise assumes that credential relabelling has only occurred within the professional occupation group. After constructing our estimate of the premium to 'traditional' degrees in professional occupations according to Equation 4, we then construct new estimates for education premia over all workers. We use the originally estimated education premia for all other occupation groups from the top panels of Tables 3 and 4 . We also use the original weights for all other occupation groups from the bottom panels of those tables. The only weights that we change in this hypothetical exercise are the weights on degree and higher holders and on other post-secondary holders within the professional occupation group. The revised weights for professionals with degrees and for professionals with other post-school qualifications are given 
by the following:

$$
\begin{aligned}
& w_{p, d, 2}^{c f}=\left(\frac{s_{d, 1}}{s_{d, 2}}\right) w_{p, d, 2} \\
& w_{p, o, 2}^{c f}=w_{p, o, 2}+\left(w_{p, d, 2}-w_{p, d, 2}^{c f}\right)
\end{aligned}
$$

In these equations, $w_{p, d, 2}^{c f}$ is the revised weight for professionals with degrees in 2002-04, $w_{p, d, 2}$ is the original weight for professionals with degrees, $w_{p, o, 2}^{c f}$ is the revised weight for professionals with other post-school qualifications and $w_{p, o, 2}$ is the original weight for professionals with other post-secondary qualifications. Our estimated education premia are then weighted averages over all occupations, using the revised weights for professionals $\left(w_{p, d, 2}^{c f}\right.$ and $\left.w_{p, o, 2}^{c f}\right)$, the revised estimate of the premium to a degree for professionals $\left(p_{t d, 2}^{*}\right)$, and original weights and education premia estimates for all other occupation groups.

Our counterfactual estimates of education earnings premia after "unwinding" the relabelling for full-time employees are provided in Tables 6 and 7 for males and females respectively. In the top panels of the Tables are the calculations for employees in professional occupations only. The actual premia estimates in column (3) are taken directly from Tables 3 and 4 . These premia are thus relative to workers in labouring occupations with no post-secondary qualifications. For example, in 2002-04, female other post-secondary qualification holders in professional occupations earned $0.542 \log$ points more (72 percent more) than employees with no post-secondary credentials working in labouring occupations. The weights presented in columns (2) and (4) of the tables are actual full-time female employment shares (expressed as percentages) taken from the appropriate Census. For example, in 1986, 8.92 per cent of all female full-time employees both held a bachelor degree or higher and were working in a professional occupation. In the bottom panel of Table 7 are the calculations for average earnings premia over all full-time employees. The earnings premia here are relative to all employees without a post-secondary education credential across all occupations.

The counterfactual earnings premia for 2002-4 after "unwinding" credential relabelling are provided in column (5) of Tables 6 and 7. The hypothetical weights provided in column (6) refer to the employment weights used in the counterfactual calculations. The end results of the 
exercise are presented in the bottom panel of the table. The following discussion will focus on the results for females.

Consider first the effect of "unwinding" the assumed relabelling on the earnings premium of other post-secondary qualification holders. Note that the overall size of the professional occupation group grew over the 1986 to 2001 period for females, from 24.12 to 29.31 per cent of the full-time workforce. Within the professional occupation group, the proportion holding a certificate or diploma was 53 percent in 1986 but only 19.5 percent in 2001. If this proportion had remained at 53 percent, then the proportion of all employees in professional occupations with a certificate or diploma would have been 15.33 percent (hypothetical weight in column (6)) rather than 5.71 percent (actual weight in column (4)). When we re-calculate the average earnings premia of certificate and diploma holders in all occupations after raising their weight in professional occupations from 5.71 percent to 15.33 percent, the earnings premium rises to 0.144 log points rather than 0.092 (bottom panel of Table 7). Recall that the other post-secondary earnings premium within the professional occupation group is unchanged in these calculations (top panel). The premium increases for workers in all occupations because professionals with these qualifications have relatively high earnings compared with other workers with these qualifications, such that increasing the weight given to professionals will increase the average earnings of all certificate and diploma holders.

For holders of bachelor degrees and above, we essentially remove the effect of these hypothetically relabelled workers from the estimated average earnings of employees in that category. If credential relabelling had not occurred, the weight on degree and higher holders within the professional occupations would have been approximately 10.84 percent rather than 20.46 percent. These hypothetical weights were calculated such that the increase in the weight placed on certificate and diploma holders exactly offsets the decrease in the weight placed on bachelor degree holders. We leave the weight on professionals with no post-secondary credentials at its actual level in 2001. We thus, as per Equation 4, re-calculate the average earnings premium of degree holders within professional occupations in 2002-4 on the assumption that 47 percent $(9.62 / 20.46)$ of degree holders in 2002-04 hold relabelled degrees and are therefore in 
Table 6: Hypothetical Effect of Credential Relabelling on Male Earnings Premia

\begin{tabular}{|c|c|c|c|c|c|c|}
\hline & $\begin{array}{l}\text { Premia } \\
1986 \\
(1)\end{array}$ & $\begin{array}{c}\text { Weights } \\
1986 \\
(2)\end{array}$ & $\begin{array}{l}\text { Premia } \\
2002-4 \\
(3)\end{array}$ & $\begin{array}{c}\text { Weights } \\
2001 \\
(4)\end{array}$ & $\begin{array}{c}\text { Re-calc. } \\
\text { premia } \\
2002-4 \\
(5)\end{array}$ & $\begin{array}{l}\text { Hypothetical } \\
\text { weights } \\
2001 \\
(6)\end{array}$ \\
\hline \multicolumn{7}{|c|}{ Professionals } \\
\hline Degree & & 7.69 & 0.679 & 12.38 & 0.720 & 9.56 \\
\hline Other P-S & & 5.47 & 0.542 & 4.07 & 0.542 & 6.89 \\
\hline None & & 2.10 & 0.480 & 2.40 & 0.480 & 2.40 \\
\hline TOTAL & & 15.26 & 0.624 & 18.85 & 0.624 & 18.85 \\
\hline \multicolumn{7}{|c|}{ All occupations } \\
\hline Degree & 0.416 & 11.54 & 0.440 & 21.85 & 0.460 & 18.97 \\
\hline Other P-S & 0.117 & 37.48 & 0.125 & 38.16 & 0.138 & 41.04 \\
\hline None & - & 51.06 & - & 40.00 & - & 40.00 \\
\hline TOTAL & - & 100.0 & - & 100.0 & - & 100.0 \\
\hline
\end{tabular}

Notes: Calculations are of the estimated effect of the assumed relabelling of education credentials of workers in professional occupations on overall education earnings premia. Premia estimates are obtained from the Income Surveys and weights are obtained from the Censuses. Log earnings premia in the top panel are relative to labourers with no post-secondary qualifications, taken directly from Table 3. Log earnings premia in the bottom panel are relative to all full-time employees (all occupation groups) with no post-secondary qualifications. These premia are constructed as weighted averages of the premia estimated in Table 3 using the relevant employment weights. Weights are presented in percentage point terms.

fact obtaining the other post-secondary premium. Since this premium is lower than the average estimated premium to a degree, this removal has the effect of raising the estimated premium for the remaining 53 percent of degree-holders who have 'traditional' degrees, from 0.570 log points to $0.729 \log$ points.

Using this alternative higher premium for bachelor degree holders in professional occupations, we can construct estimates of the education premium across all occupations in the absence of credential relabelling. We use the counterfactual weights and the higher premium for professionals and the actual weights and originally estimated premia for all other occupation groups. The premium for degree holders would be 0.466 rather than 0.405 , a significantly higher number and indeed higher than the earnings premium in 1986. It thus appears that credential relabelling 


\section{Table 7: Hypothetical Effect of Credential Relabelling on Female Earnings Premia}

\begin{tabular}{|c|c|c|c|c|c|c|}
\hline & $\begin{array}{l}\text { Premia } \\
1986 \\
(1)\end{array}$ & $\begin{array}{c}\text { Weights } \\
1986 \\
(2)\end{array}$ & $\begin{array}{l}\text { Premia } \\
2002-4 \\
(3)\end{array}$ & $\begin{array}{c}\text { Weights } \\
2001 \\
(4)\end{array}$ & $\begin{array}{c}\text { Re-calc. } \\
\text { premia } \\
2002-4 \\
(5)\end{array}$ & $\begin{array}{l}\text { Hypothetical } \\
\text { weights } \\
2001 \\
(6)\end{array}$ \\
\hline \multicolumn{7}{|c|}{ Professionals } \\
\hline Degree & & 8.92 & 0.570 & 20.46 & 0.729 & 10.84 \\
\hline Other P-S & & 12.80 & 0.392 & 5.71 & 0.392 & 15.33 \\
\hline None & & 2.40 & 0.342 & 3.14 & 0.342 & 3.14 \\
\hline TOTAL & & 24.12 & 0.511 & 29.31 & 0.511 & 29.31 \\
\hline \multicolumn{7}{|c|}{ All occupations } \\
\hline Degree & 0.451 & 11.89 & 0.405 & 31.45 & 0.466 & 21.83 \\
\hline Other P-S & 0.197 & 27.91 & 0.092 & 22.70 & 0.144 & 32.32 \\
\hline None & - & 60.21 & - & 45.84 & - & 45.84 \\
\hline TOTAL & - & 100.0 & - & 100.0 & - & 100.0 \\
\hline
\end{tabular}

Notes: Calculations are of the estimated effect of the assumed relabelling of education credentials of workers in professional occupations on overall education earnings premia. Premia estimates are obtained from the Income Surveys and weights are obtained from the Censuses. Log earnings premia in the top panel are relative to labourers with no post-secondary qualifications, taken directly from Table 4. Log earnings premia in the bottom panel are relative to all full-time employees (all occupation groups) with no post-secondary qualifications. These premia were constructed as weighted averages of the premia estimated in Table 4 using the relevant employment weights. Weights are presented in percentage point terms.

could have had a significant depressive effect on the trend in measured education premia over the period from 1986 to 2002-04 for females.

The results of conducting the same "unwinding" exercise for male full-time employees are provided in Table 6. The effect on education earnings premia is more muted here, reflecting the substantially lower incidence of potential credential relabelling among males. Males were less likely than females to have been employed in nursing in particular, but also in teaching. Note, however, that there was no decline in the originally estimated education earnings premia for males, but rather simply a constancy over the 1982 to 2002-04 period. Indeed, this arguably provides additional support for the contention that credential relabelling has depressed female education earnings premia, since premia appeared to have fallen for females and the potential 
scale of relabelling was much larger.

\section{Conclusions}

Education earnings premia appear to have remained very stable in Australia over the 1982 to 2002-04 period, after falling from very high levels in the 1960s. This is in stark contrast to what has been observed in the United States, where the college premium increased considerably, particularly in the 1980s. The leading explanation for the stability of education premia in Australia is that the supply of highly educated workers has increased as demand has increased with skill-biased technical change, keeping wage premia constant. Although this explanation seems plausible, it is puzzling that supply of educated workers has grown so strongly in the face of stable earnings premia and rising costs, as the Higher Education Contribution Scheme was introduced and the level of student contributions increased over the 1990s. More Australians have been investing in higher education at the same time as the returns to such education appear to be falling. ${ }^{12}$ Given this puzzle, there may well be additional reasons for the observed stability of education earnings premia.

We have suggested one particular change in the Australian higher education system over this period that may have affected estimates of education earnings premia. Some of the observed increase in the proportion of workers holding a bachelor degree or higher in Australia may be due to a particular change in the labelling of education credentials of certain professional workers, including nurses and teachers. We constructed an estimate of the potential effect of this credential relabelling on education earnings premia. Such relabelling may have held down estimates of education earnings premia for females by around 6 percentage points. It was estimated to have a less significant effect on male earnings premia.

There are other potential explanations for the stability of education earnings premia in Australia that also deserve attention. As noted above, one significant change in the Australian labour market over the past two or three decades has been the large reduction in labour market par-

\footnotetext{
${ }^{12}$ Gregory (1995) argues that the return to education is in fact rising as the probability of employment, particularly full-time employment, is increasingly related to education attainment.
} 
ticipation of less educated adult males in particular. Selection into full-time jobs may thus have changed, particularly for the least educated. The average quality of workers with no postsecondary credentials who still hold a full-time job in recent years may be higher than in the past, and thus may earn better wages on average. The minimum wage may have had a role here also. Recall that the standard method of estimating education earnings premia is to measure earnings of highly educated workers relative to the no post-secondary education group. If this base group is increasing in average quality, this may also hold down estimates of earnings premia. This is an area for future research.

In a similar vein, the average quality of workers with bachelor degrees and above may be falling over the period, as a much higher proportion of the population now hold such credentials. If labour market earnings reflect this underlying quality, then potential falling average quality of bachelor degree holders may also hold down estimates of education earnings premia.

Skilled immigration and emigration (so-called "brain-drain") is also a feature of the Australian labour market that is quite different to the experience in the United States. If earnings are lower for immigrants of all education levels, as appears to be the case, an increasing focus on skill-based immigration may also impact estimated earnings premia in Australia, when measured for all current full-time workers. If our brightest highly educated Australian born workers are more likely to emigrate to the United States and United Kingdom, where earnings for the most skilled are higher, this may also affect earnings levels by education group. To sum up, there is more work to be done to fully understand what appears to be a puzzle in Australia: the apparent stability of education earnings premia.

\section{References}

[1] Australian Bureau of Statistics (1993) ABS Classification of Qualifications (ABSCQ), 1993, Catalogue Number 1262.0, Australian Bureau of Statistics, Canberra.

[2] Borland, Jeff (1996) "Education and the Structure of Earnings in Australia," The Economic Record, 72 (219), pp. 370-380, December. 
[3] Borland, Jeff (1999) "Earnings Inequality in Australia: Changes, Causes and Consequences," The Economic Record, 75 (229), pp. 177-202, June.

[4] Borland, Jeff (2002) "New Estimates of the Private Rate of Return to University Education in Australia," Melbourne Institute of Applied Economic and Social Research (MIAESR), The University of Melbourne, Working Paper No. 14/02, July.

[5] Borland, Jeff, Peter Dawkins, David Johnson and Ross Williams (2000) "Returns to Investment in Higher Education,” The Melbourne Economics of Higher Education Research Program Report No. 1, Report to the Vice Chancellor, the University of Melbourne.

[6] Borland, Jeff, Robert Gregory and Peter Sheehan (2001) "Inequality and Economic Change," in Work Rich, Work Poor: Inequality and Economic Change in Australia, Eds J. Borland, R. Gregory and P. Sheehan, Centre for Strategic Economic Studies, Victoria University, Melbourne.

[7] Card, David and John DiNardo (2002) "Skill-Biased Technological Change and Rising Wage Inequality: Some Problems and Puzzles," Journal of Labor Economics 20 (4), pp. 733-783.

[8] Chapman, Bruce and Tai-Tee Chia (1989) "Financing Higher Education: Private Rates of Return and Externalities in the Context of the Tertiary Tax," Centre for Economic Policy Research, Discussion Paper No. 213, The Australian National University, June.

[9] Chapman, Bruce and Tony Salvage (1997) “The Consequences of Recent Changes in Financing for Australian Higher Education," Centre for Economic Policy Research, Discussion Paper No. 367, The Australian National University, June.

[10] Chia, Tai-Tee (1991) "Has the Value of a Degree Fallen? Cross-Sectional versus TimeSeries Evidence," in International Economics Postgraduate Research Conference Volume Eds. K. Clements, R. Gregory and T. Takayama, supplement to The Economic Record, pp. 41-52. 
[11] Colegrave, Andrew (2006) "Why Study at a Mature Age? An Analysis of the Private Returns to University Education in Australia," mimeo, Business School, The University of Western Australia.

[12] Commonwealth Tertiary Education Commission (1986) Review of Efficiency and Effectiveness in Higher Education, Report of the Committee of Enquiry, September.

[13] Gregory, Robert (1995) "Higher Education Expansion and Economic Change," Australian Bulletin of Labour, 21 (4), pp. 295-322, December.

[14] Karmel, Tom (1994) "Education and Economic Growth," in Investment for Growth, Economic Planning and Advisory Council Background Paper No. 39, Australian Government Publishing Service, Canberra, pp. 103-128, April.

[15] Karmel, Tom (1995a) “The Demand for Secondary Schooling," in The Economics of Education and Training 1995, Eds F. Ferrier and C.S. Smith, Australian Government Publishing Service, Canberra, pp. 144-158, August.

[16] Karmel, Tom (1995b) The Impact of Increasing Education Levels on the Australian Workforce, Unpublished $\mathrm{PhD}$ dissertation, The Australian National University.

[17] Katz, Lawrence and Kevin Murphy (1992) “Changes in Relative Wages, 1963-1987: Supply and Demand Factors," The Quarterly Journal of Economics, 107 (1), pp. 35-78, February.

[18] Kennedy, Steven and David Hedley (2003) “A Note on Educational Attainment and Labour Force Participation in Australia," Treasury Working Paper No. 2003-03, The Australian Treasury, Canberra, November.

[19] Leigh, Andrew and Chris Ryan (2007) "Estimating Returns to Education Using Different Natural Experiment Techniques," Economics of Education Review, forthcoming.

[20] Maglen, Leo (1991) “The Impact of Education Expansion on the Distribution of Earnings in Australia," Australian Bulletin of Labour, 17 (2), pp. 132-159, June. 
[21] Maglen, Leo (1994) "Education Expansion and the Private Returns on a University Degree," Economic Papers, 13 (4), pp. 57-71, December.

[22] Miller, Paul (1984) "Education and the Distribution of Earned Income," pp. 16-36 in Understanding Labour Markets in Australia, Eds R. Blandy and O. Covick, George Allen \& Unwin, Sydney.

[23] Miller, Paul, Charles Mulvey and Nick Martin (1995) "What do Twins Studies Reveal about the Economic Returns to Education? A Comparison of Australian and US Findings," The American Economic Review, 85 (3), pp. 586-599, June.

[24] Miller, Paul, Charles Mulvey and Nick Martin (2005) "Birth Weight and Schooling and Earnings: Estimates from a Sample of Twins," Economics Letters, 86 (3), pp. 387-392, March.

[25] National Review of Nursing Education (2001) "Recent Australian Changes to Nurse Education and Training," Information Paper No. 1, National Review of Nursing Education, jointly commissioned by the Minister for Health and Ageing and the Minister for Education, Science and Training, Commonwealth Government of Australia.

[26] Neville, John and Peter Saunders (1998) "Globalization and the Return to Education in Australia," The Economic Record, 74 (226), pp. 279-285, September.

[27] Norris, Keith, Ross Kelly and Margaret Giles (2005) Economics of Australian Labour Markets, 6th Edition, Pearson Addison-Wesley, Sydney Australia.

[28] Ryan, Chris (2002) "Individual Returns to Vocational Education and Training Qualifications: their Implications for Lifelong Learning," National Centre for Vocational Education Research (NCVER), Adelaide. 


\section{Appendix A - Data Sources}

\section{Student Enrolment Data in Table 1}

(a) Universities Commission “Annual Report of Universities Commission,” 1966 and 1971.

(b) Commonwealth Advisory Committee on Advanced Education “2nd Report: 1970-72," Government Printing Office, Canberra.

(c) Commonwealth Advisory Committee on Advanced Education “3rd Report: 1973-75," Government Printing Office, Canberra.

(d) Commission on Advanced Education “1977-1979 Report,” Australian Government Publishing Service, Canberra.

(e) Commonwealth Tertiary Education Commission "Selected University Statistics," 1976, 1981 and 1986.

(f) Commonwealth Tertiary Education Commission "Selected Advanced Education Statistics," 1981 and 1986.

(g) Commonwealth Tertiary Education Commission "Selected Higher Education Statistics: 1991," AGPS, Canberra.

(h) Department of Employment, Education, Training and Youth Affairs "Selected Higher Education Statistics: 1996," AGPS, Canberra.

(i) Department of Education, Science and Training "Selected Higher Education Statistics," AGPS, Canberra, 2001 and 2006.

\section{ABS Income Surveys}

At the time of estimation, public-access unit record files were available for Income Surveys conducted in 1982, 1986, 1990, 1994-95, 1995-96, 1997-98, 1997-98, 1999-2000, 2000-01, 2002-03 and 2003-04. The first three surveys were conducted over a two month period in the December quarter of the year, while the last eight surveys were each conducted over twelve month periods. The in-scope population for all surveys comprised persons resident in private dwellings in Australia, although the last eight surveys excluded military personnel residing in private dwellings, while the first three surveys included such persons as well as persons residing in "special" dwellings, defined as accommodation provided by educational institutions, hospitals, short-stay caravan parks, etc. 
Table 8: ABS Income Surveys

\begin{tabular}{lll}
\hline \hline Survey name & Survey period & Sample size \\
\hline Income and Housing & October-December 1982 & 31,720 \\
Income Distribution & October-December 1986 & 17,714 \\
Income and Housing Costs & October-December 1990 & 30,444 \\
Income and Housing Costs & July 1994 - June 1995 & 13,827 \\
Income and Housing Costs & July 1995 - June 1996 & 14,017 \\
Income and Housing Costs & July 1996 - June 1997 & 14,595 \\
Income and Housing Costs & July 1997 - June 1998 & 13,931 \\
Income and Housing Costs & July 1999 - June 2000 & 13,070 \\
Income and Housing Costs & July 2000 - June 2001 & 13,183 \\
Income and Housing & July 2002 - June 2003 & 19,378 \\
Income and Housing & July 2003 - June 2004 & 22,286 \\
\hline \hline
\end{tabular}

Note: Sample size refers to all all persons over 15 years of age in respondent households.

To increase the precision of estimates obtained from the surveys conducted from 1994-95 on, the following consecutive-year data sets were been pooled together: 1994-95 and 1995-96; 1996-97 and 1997-98; 1999-2000 and 2000-01; and 2002-03 and 2003-04.

All surveys collected information on weekly earnings. However, the 1982 survey collected information on "current actual" weekly earnings, whereas the other surveys collected information on "current usual" weekly earnings. Earnings are reported for all employed persons - that is, there are no missing values - with the ABS imputing values for non-respondents. Only in 1982 are imputations identifiable in the data set. Full-time workers are defined as persons who usually work 35 or more hours per week.

The level of detail on highest educational attainment varies considerably across the survey years. Only three consistently defined categories are distinguishable across all survey years: bachelor degrees or higher, other post-secondary qualification, and no post-secondary qualifications.

Occupation of main job is classified into one of 62 categories in 1982. In 1986, 1990, 199495 and 1995-96, occupation is classified according to the 1-digit level ABS Australian Standard Classification of Occupations First Edition (ASCO1) (8 categories). From 1996-97, occupation is classified according to the 1-digit level ABS Australian Standard Classification of Occupations Second Edition (ASCO2) (9 categories).

\section{Census of Population and Housing}

At the time of writing, public-access unit record files were available for Census of Popula- 
tion and Housing one percent samples for 1981, 1986, 1991, 1996 and 2001. Only full-time employees were included in the analysis. Full-time employment is defined by individuals reporting working 35 hours or more per week. Only individuals reporting that they are employees are included (the self-employed were excluded).

Income is recorded in annual terms in the 1981, 1986 and 1991 Censuses, while it is recorded in weekly terms in 1996 and 2001. Zero income was set to missing in 1981. Negative and nil incomes were set to missing in 1996 and 2001. Income is reported in categories as follows: 1981 has 13 categories, 1986 has 8 categories, while 1991, 1996 and 2001 have 14 categories. To transform the categorised reported income in the Census to a "continuous" variable for analysis, we employed midpoints for each reported category. For the highest income category (open ended category at the top) we simply use the point that is the same distance above the bottom end of the range used in the second highest income category (the midpoint). For example, in the 1996 and 2001 Censuses, we use an income level of $\$ 1,750$ for the top category of $\$ 1,500$ and more. The second highest category is $\$ 1,000$ to $\$ 1,499$, for which we used a midpoint of $\$ 1,250$.

The 1996 and 2001 Censuses record occupations according to the ASCO2 definitions. The 1986 and 1991 two digit occupation groups provided using ASCO1 definitions were mapped into the ASCO2 one digit categories employed in the 1996 and 2001 categories according to Table 9. Note that the advanced clerical and intermediate clerical groups under ASCO2 were combined to assist this mapping. Notable in the changes between the two occupation definitions here is the movement of nurses from the third category (para-professionals in ASCO1) in the 1986 and 1991 Censuses to the second category (professionals in ASCO2) in the 1996 and 2001 Censuses.

The 1981 occupations provided in the Census public use files were also mapped into the ASCO2 one digit occupation categories according to Table 9, with the mapping being less successful than that for the 1991 and 1996 Censuses, particularly for the split between professional and associate professional categories. 
Table 9: Major occupational classifications mapping - to ASCO2 definitions

\begin{tabular}{clll}
\hline \hline ASCO2 & ASCO2 & $\begin{array}{l}1986 \& 1991 \\
\text { occ. numbers }\end{array}$ & $\begin{array}{l}1981 \\
\text { occ. numbers }\end{array}$ \\
\hline 1 & Managers \& administrators & $1-5,7$ & $13-14,21$ \\
2 & Professionals & $8-17,21-22$ & $1-11,31,68$ \\
3 & Associate professionals & $6,18-20,23-24,44$ & $12,18,61,67$ \\
4 & Tradespersons \& related & $25-34$ & $23,28,40,42-50,52,65,71$ \\
$5 \& 6$ & Advanced PLUS Intermediate & $35-38,40,42-43$, & $15-17,19,35$, \\
& $\quad$ clerical, sales \& service & $45,47,49$ & $63,69-70$ \\
7 & Intermediate production \& transport & $50-54$ & $24-27,29-30,32-33,38-39$, \\
& & & $41,51,53-55,57$ \\
8 & Elementary clerical, sales \& service & $39,41,46,48$ & $20,34,36-37,62,66$ \\
9 & Labourers \& related & $55-60$ & $22,56,58-60,64$ \\
\hline \hline
\end{tabular}




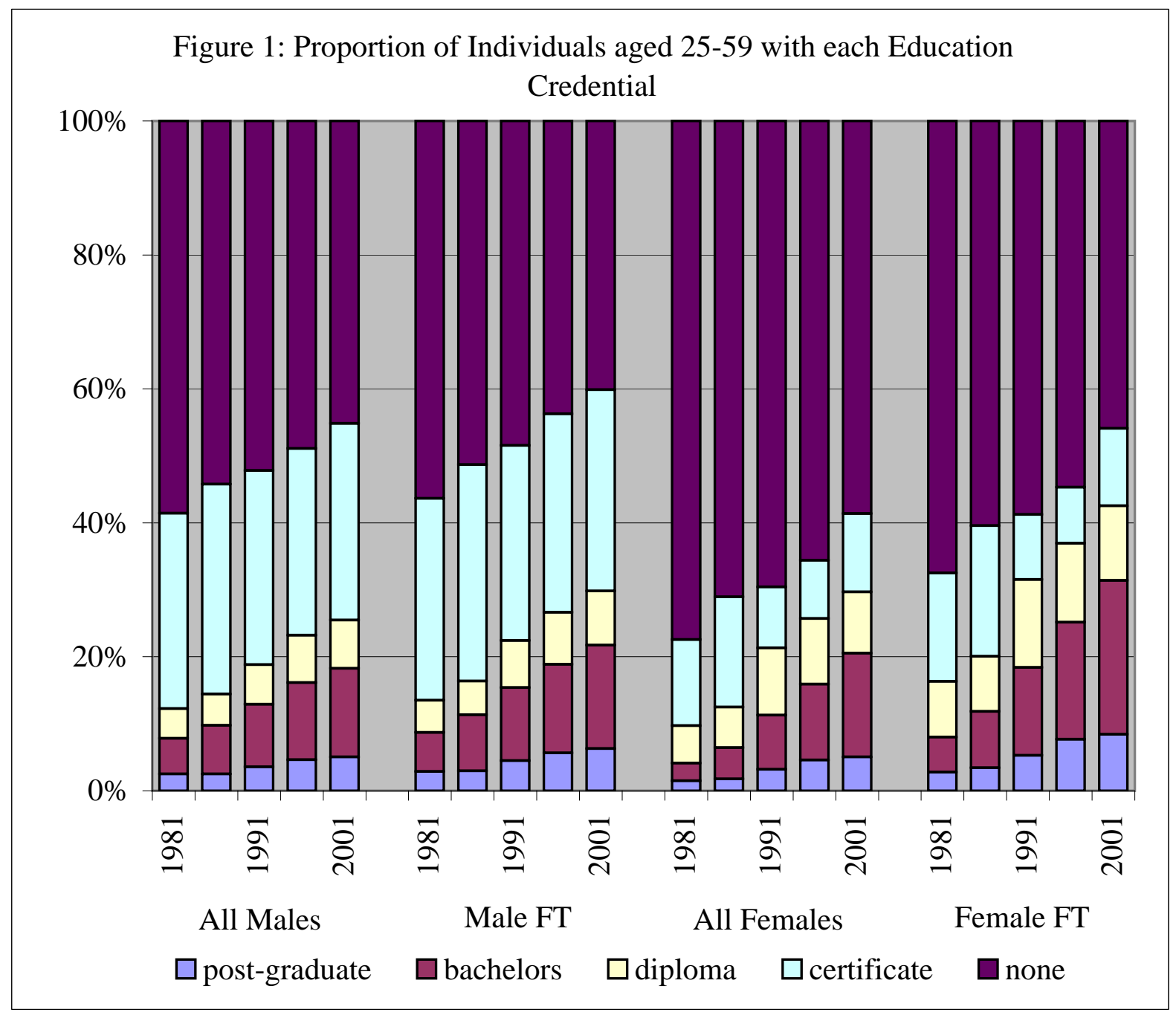

Source: Australian Censuses of Population and Housing: 1981, 1986, 1991, 1996 and 2001, public use CURFs.

Note: $\quad$ FT refers to full-time workers 
Figure 2: Proportion of Individuals with Bachelors degrees or above - by birth cohort
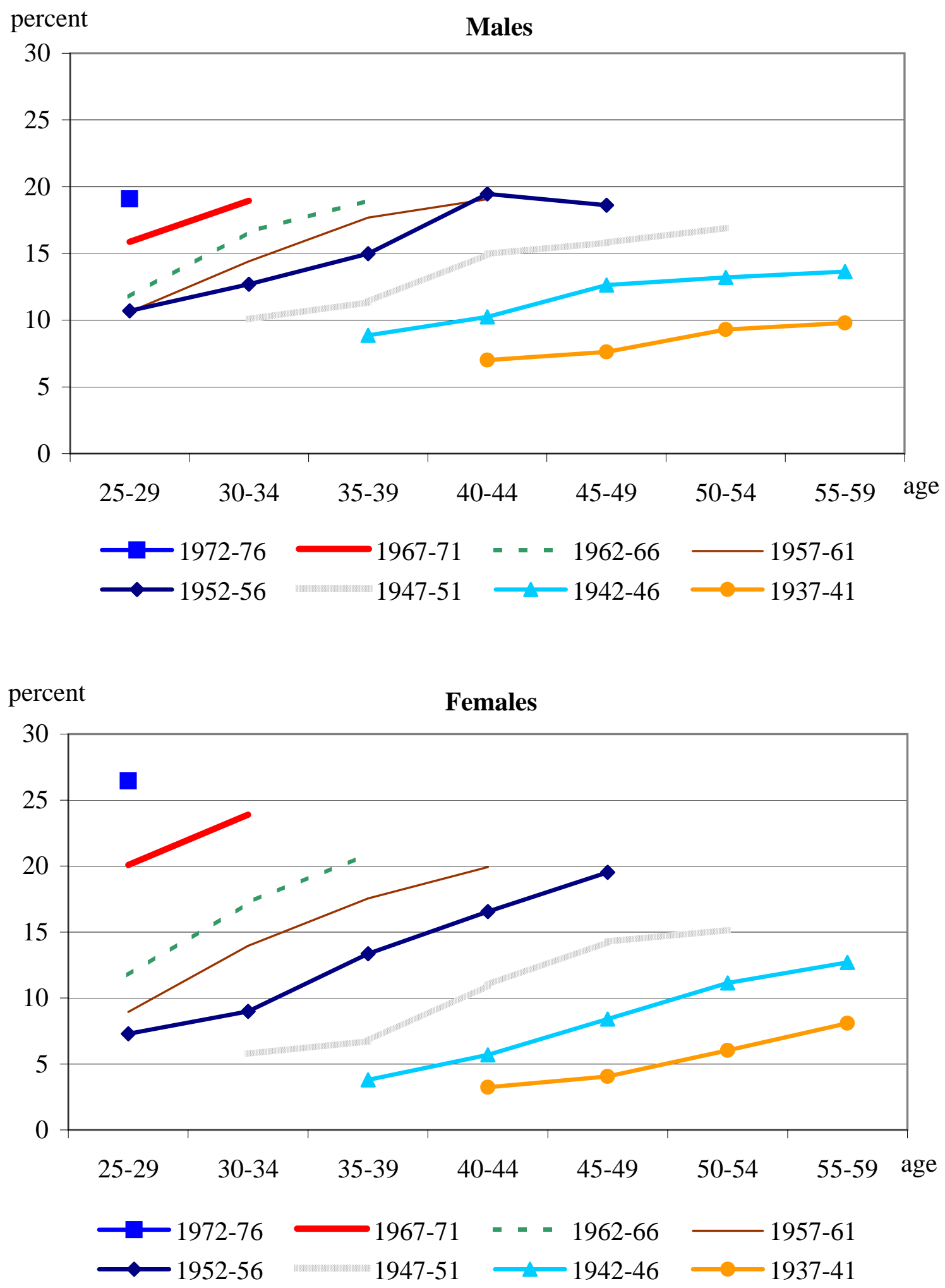

Source: Australian Censuses of Population and Housing: 1981, 1986, 1991, 1996 and 2001 pubic use CURFs 

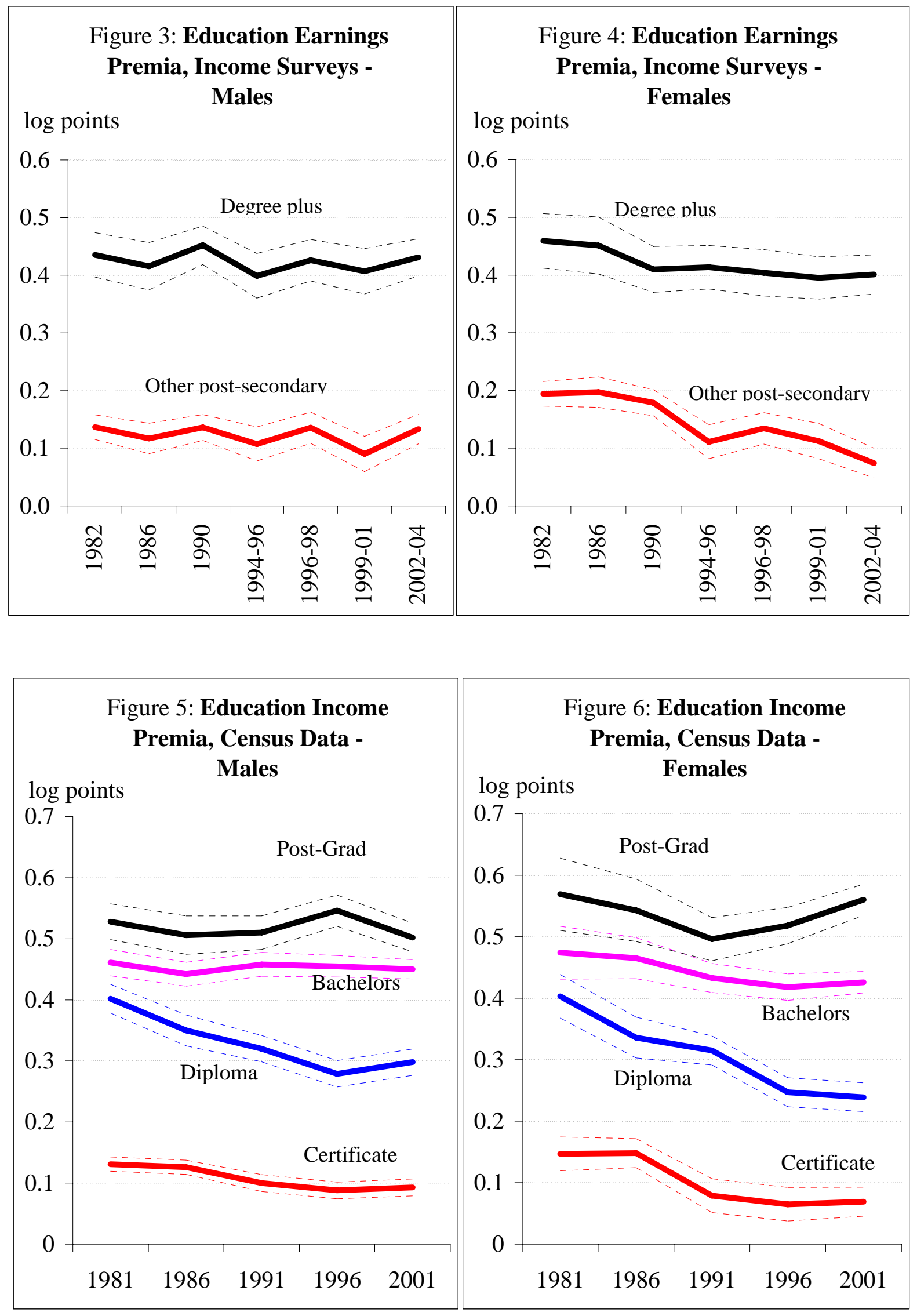


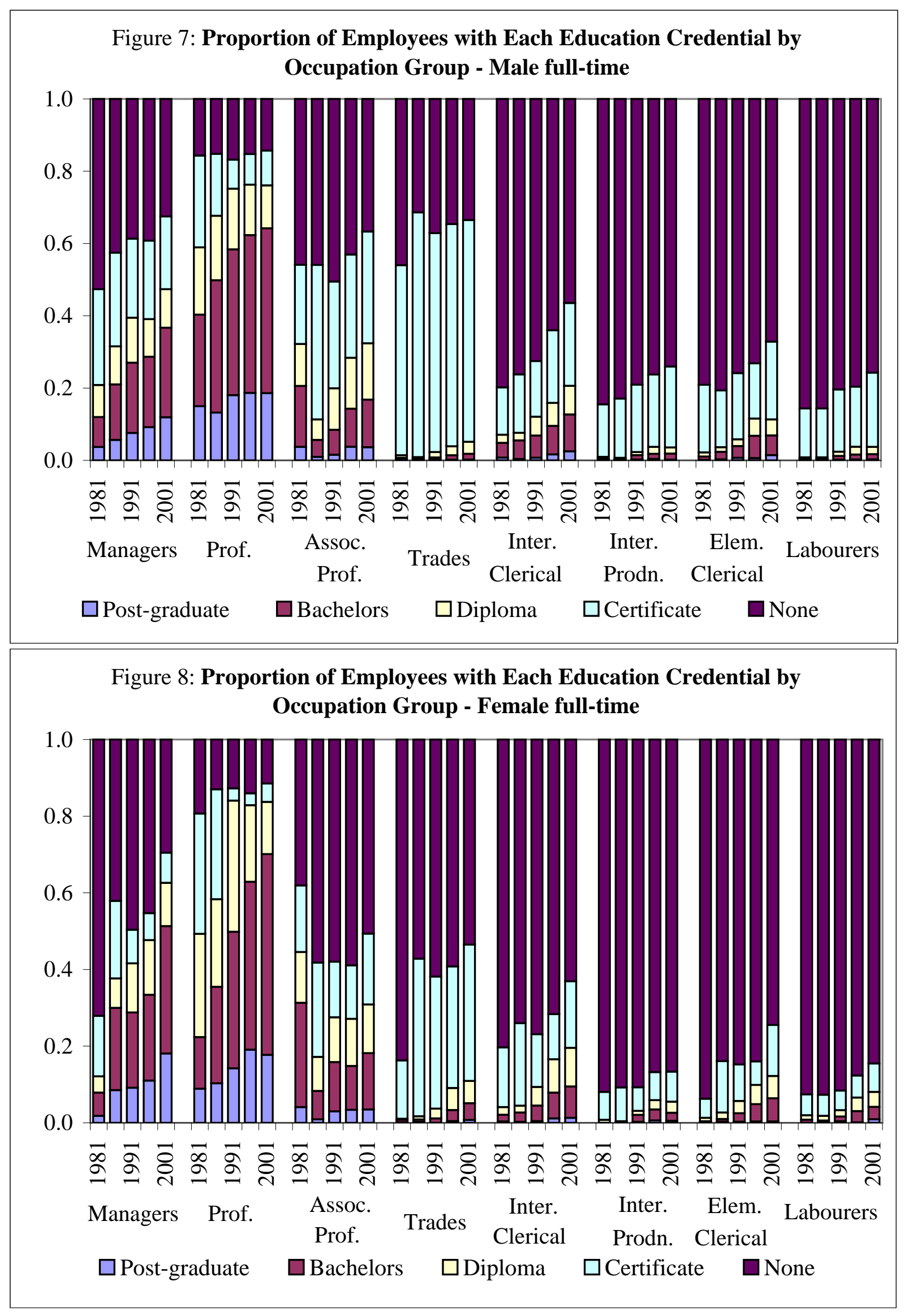



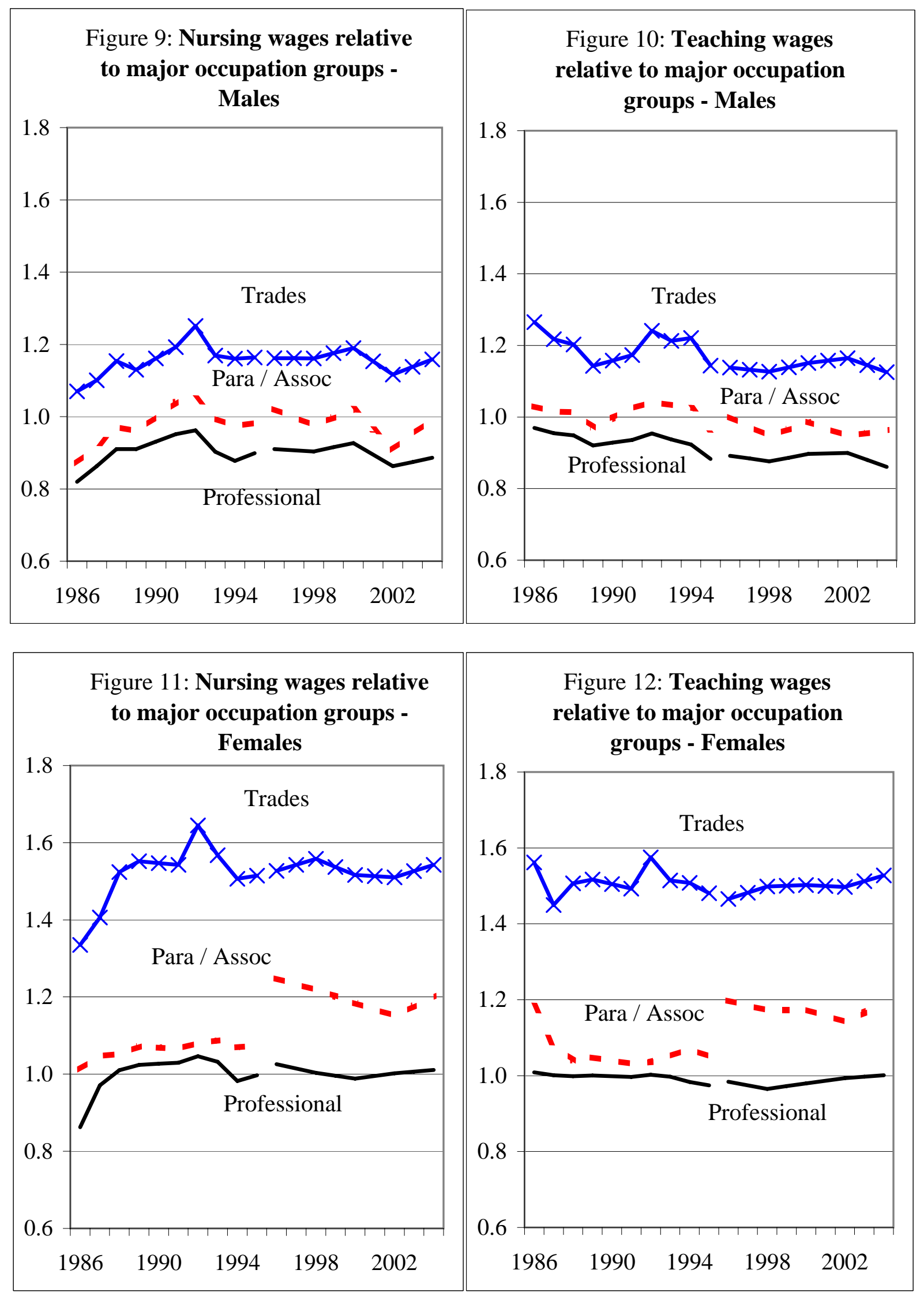